\title{
A Commentary on Poudrier's “Tapping to Carter: Mensural Determinacy in Complex Rhythmic Sequences”
}

\author{
TIMO FISCHINGER[1] \\ Max Planck Institute for Empirical Aesthetics \\ Frankfurt, Germany \\ ANNETTE VAN DYCK-HEMMING \\ Max Planck Institute for Empirical Aesthetics \\ Frankfurt, Germany
}

\begin{abstract}
This paper is a brief commentary on Poudrier's (2017) research article titled "Tapping to Carter: Mensural Determinacy in Complex Rhythmic Sequences." Poudrier's study aimed "to explore the relative salience of an implied beat in two contrasting rhythmic sequences” (p. 277) taken from one of Elliott Carter's compositions using a pulse finding paradigm. In our commentary, we critically evaluate the current approach and discuss further interpretations based on the author's results. Primarily, we argue that it is very difficult to draw any clear conclusions from the data (on a mathematical/statistical basis) because the recorded tapping behavior, namely the overall synchronization rate of the participants was far below chance level. These results therefore need to be interpreted with caution, which also implies that emergence of temporal expectations in terms of the concept of "mensural determinacy," originally conceptualized by Hasty (1997), still needs further clarification. Nevertheless, this study may serve as a fruitful example for a pulse finding study, offering some helpful insights into the methodological issues when applying a tapping paradigm to highly complex art/modern music.
\end{abstract}

Submitted 2018 February 2; accepted 2018 March 18.

KEYWORDS: commentary, Carter, tapping, polyrhythms

TAPPING experiments have a long history that extends back to studies conducted by researchers such as Stevens (1886). Since then, studies on synchronization using real/actual music are scarce, as Poudrier (2017) rightly points out (cf., Previous Studies, p. 281). The vast majority of tapping studies used pacing signals emitted by metronomes. These usually provide pulse sequences comprised of isochronous inter-beat-intervals that are highly predictable (for a review: see Repp, 2005; Repp \& Su, 2013).

The reason for the lack of tapping studies that are concerned with real music (as a stimulus) largely lies in the limited control of stimuli. The high degree of ecological validity goes along with a high complexity of stimulus material, since the different musical features such as melody, pitch, timbre, form, rhythm, and meter appear united and more or less inseparable from one another. Music is always heard as a whole, causing various effects on the perception of the music, and hence, on tapping or synchronization behavior.

Given the fact that these effects are generally very difficult to disentangle when analyzing the data, psychologists like to use simple metronome patterns that are easier to control and that can easily be described (e.g., on a mathematical basis). Thus, metronome tapping is considered a relevant and elementary method for the investigation of fundamental aspects of sensorimotor synchronization that represent essential requirements as a basis for more complex coordination of movements while making music (Repp, 2005; Keller \& Burnham, 2005). However, the transferability of the respective results to a musical context cannot always be guaranteed. 
As for pulse finding within real music, the tapping paradigm is an adequate method and well chosen by the author. Moreover, we welcome Poudrier's effort in using this kind of experimental paradigm to empirically investigate theoretical assumptions that derived from music analysis. The present study is mainly based on an extensive analysis of the piece "90+" by Elliott Carter (cf., Poudrier, 2009). One of the main outcomes of this analysis was the so-called stratification of different layers/meters within the piano piece. [2]

Certainly, long-range polyrhythms and stratification are known to be constituent factors in Carter's compositions (Link, 1994; Mead, 2012). The composition for piano solo "90+" is indeed based on at least one obvious short-range meter, as mentioned in the programmatic note at the beginning of the composition. Since this piano piece was written for the 90th birthday of Geoffredo Petrassi, an old and dear friend of Carter and acknowledged Italian composer who is very well-known in the modern music scene, the composition is called "90+." The musical process is divided in 90 timespans (not measures): one part including the relative duration of 5 quarters one triplet eighth, namely 5 1/3. In Carter's work, measures are always only a means to write down a piece, never implying a regular beat on a perceptual level.

It is most likely that Petrassi knew about Carter's principles of composition by heart. "90+" may therefore be deemed a kind of musical statement for a highly specialized and most widely elite discourse of professional musical individuals with deep knowledge of post-serialist music. It may be assumed that Carter chose short ranges for his polymeters in this composition to see if his friend Petrassi would be able to recognize his elaborate shifting. With this in mind, Poudrier's idea may have been that a well-trained music listener with specific interest and knowledge of modern American music could transform his perception of the piece or of timespans of it into a regular motoric performance. Here, Poudrier assumes an ideal listener, one who exhibits a very high degree of musical expertise and principally can hear almost everything. To test this, it is worth conducting a music psychological study with musical experts and non-experts.

However, one may not forget, that Elliott Carter's music is primarily music for experts, anyways: Firstly, more than once in his long life, lasting from 1908 to 2011, Carter has stated the clear standpoint that he is interested in "'advanced' music" (Carter, 1977, p. 276); famous among Carterians is his sentence referring to String Quartet (No. 1), the composition which founded his reputation: "I decided for once to write a work very interesting to myself, and to say to hell with the public and with the performers, too." (Carter and Fulton, 1972, p. 35) Carter always aimed at the need to hear his music again and again, otherwise he would have considered it being boring (Carter, 1997c). Carter would never have claimed that his "compositional strategies" (Poudrier, 2017, p. 279) would be perceivable least at first hearing and never would he have expected everyone to share his "aesthetic goals" (Poudrier, 2017, p. 279). Secondly, Carter's music is written music; the aesthetic concept behind it refers inter alia to the long tradition of 'Augenmusik' in the wider sense of composition that aesthetically addresses at least two channels of perception: one by reading and one by listening, and Elliott Carter shared the preference for this kind of poetics with his admired colleague and live long friend Goffredo Petrassi.[3] In "90+" this highly intellectual mixture of private and aesthetic relations is somehow celebrated and kind of sealed with Charles Rosen's recording of "90+" (1994) (from BRIDGE 9090, Music of Elliott Carter, Vol. 3).

As mentioned, studies with high ecological validity are essential. And of course, there is a high intersubjective variance with regard to individual processing capacity and the significant influence of cultural, academic-theoretical, and plain musical knowledge about music that comes into play. Transforming a piece to a mathematically timed version may be tolerable, especially regarding to the need of control. Extracting just one line of pitches might be convincing if it is a prevailing melody. Though, the creation of stimuli sometimes might threaten ecological validity. At least, one would have to be very careful drawing conclusions from the use of heavily processed stimuli addressing the original piece and moreover, a certain composer's music or style.

However, it is really hard to say if Carter himself would have believed or even thought about whether listeners would be able to perceive both rhythmic pulse streams (left and right hand) separately. This is a highly demanding and almost impossible task for "normal" music listeners (e.g., choir singers). Although, in another (highly controlled) experiment, the author was able to show that listeners are generally able to hear 
and differentiate two separate (less complex) musical streams with different (and more clear/simple) meter that are played/heard simultaneously, at least to a certain degree (cf., Poudrier \& Repp, 2013), the present results seem to be less clear due to the exploratory character of the study.

To us, the most important result of the study is perhaps that participants (choir singers and graduate music students) were generally not able to perceive a steady pulse or meter in the complex rhythmic stimuli regardless of conditions. Although there was one participant (No. 7) who was able to synchronize his finger taps to the given sequences quite well (cf., Figure 5, p. 305), most of the participants could not synchronize to the (theoretical) pulse/meter because they were not able to predict upcoming musical events and/or a regular beat/meter based on the initial notes at the beginning of the piece. The mean/relative synchronization rate across all participants was $31.9 \%$ for all taps and $25.5 \%$ for the quarter notes with a synchronization criterion of $+/-100 \mathrm{~ms}$ (cf., p. 302). Hence, the synchronization rate was far below the chance level, overall. Therefore, and this is one of our major concerns here, diverging conclusions may be drawn from the data presented in the paper.

As mentioned by the author, the question of tapping rate variability would "need to be considered more carefully" (p. 307) in future research. Moreover, Poudrier rightly emphasizes that "the analytical interpretation used as a basis for the experimental design and statistical analysis of tapping performance in this study is not the only possible interpretation of the temporal structure exhibited by the source materials." (p. 308) This also implies that it remains unclear if the emergence of temporal expectations in terms of the concept of Hasty's (1997) mensural determinacy has or has not been realized by the majority of participants. Unfortunately, the author does not discuss this sufficiently.

Differences between the synchronization behavior/rate when tapping to the extracted rhythmic pattern of each hand separately may occur because the left hand pattern includes more short time intervals at the beginning of the sequence. These may have provided a better chance for finding a beat and predicting a steady pulse. Hence, the left hand pattern was "more mensurably determinate" (p. 302) than the rhythm sequence played by the right hand, which was less predictable due to the relatively long time intervals between the first notes of the sequence.

Following Povel and Essens (1985), multiple clocks can be initiated by a rhythmic sequence, assuming "that people attempt to generate an 'internal clock' which enables the specification of the temporal structure in the pattern" (p. 437). In this study, participants first established a steady tapping pulse based on their individual internal clock(s) initiated by the first notes and then kept on tapping as well and steadily as possible for the rest of each trial, with only marginal changes in tapping behavior. Here, participants with more exposure to 20th-century music showed a more stable tapping period than participants who were less experienced with this kind of modern music. However, with the small sample size, caution must be applied, as these findings might not be transferable to the general population of music listeners. Moreover, "the possibility of a sampling error due to the specific characteristics of the participants in this study cannot be discounted." as mentioned by the author (p. 308).

Another major problem with the experimental method is the use of acoustical extractions of the piece (like only the rhythm realized as the sound of claves or presenting the rhythm with or without accents) and incorporating a fairly large number of 18 different kinds of stimuli and conditions. The piece was made as a whole. [4] Ecological validity and the range of possible conclusions are at least endangered when single streams or patterns are used because one constituent principle-composing an organic musical process (being as artificial as possible) - is completely destroyed by reducing sound to time or to just one voice instead of two. This is like saying that listening to the piano or the full score makes no difference. The composer's devices are part of the composition. If one extracts one part of music, what is the message? If one plays the left hand of an unknown piano sonata of, say, the 1770s to a listener, eliminating all accents that result from regarding the limits of the written measure, it might be interesting, but what would the question be?

Simultaneously, another reduction takes place that is especially felt in comparison with an interpretation by a real musician. Of course, the following argument results from a historic-hermeneutic point of view, but perhaps it is worth considering its plausibility: the mathematical accuracy of the computational 
reproduction of the piece is important for precise measuring and so forth. Nonetheless, it generates a constructed equal-ness that completely contradicts the whole idea of this music and of the special discourse in which individuals are able to make sense of the music. Because constructed equalness contributes, for example, to the cultural attraction of never delayed, ceaseless techno or other electronic dance music, the dramatic course the musical process takes is the main point of an artificial concept (e.g., Carter's musical concept). If these phenomena are investigated without any relationship to musical plausibility, what has been examined? Nevertheless, this study may serve as a fruitful example for a pulse finding study, offering some helpful insights into the methodological issues when applying a tapping paradigm to highly complex art/modern music.

\section{ACKNOWLEDGEMENTS}

This article was copyedited by Dana Lauren DeVlieger and layout edited by Kelly Jakubowski.

\section{NOTES}

[1] Correspondence can be addressed to Timo Fischinger at timo.fischinger@ae.mpg.de.

[2] In the article, Poudrier mentioned that there may be other possible interpretations.

[3] Carter, (1997c); Carter's mentioning of a first hearing of Serenata (1958) to which in brackets he adds "and sight" (p. 187) describes his normal way of perceiving a Petrassi-composition. See id., (1997a), too.

[4] As every composition of Carter. His aesthetic refers to a notion of 'course', of process-typical for a postserialist composer and completely contradictory to e. g. John Cage's aesthetic of chance or an aesthetic of repetition like realized in the minimal music of Steve Reich. See Link (1994), and Mead (2012).

\section{REFERENCES}

Carter, E. (1977). String Quartets No. 1 (1951) and No. 2 (1959) [1970]. In id., The Writings of Elliott Carter, Else and Kurt Stone (Eds.), Bloomington, Ind.: Indiana University Press, p. 276.

Carter, E. (1997a). Reminiscence of Italy [1988]. In J. Bernard (Ed.), Collected Essays and Lectures, 19371995 (pp. 292-294). Rochester, N.Y.: University of Rochester Press.

Carter, E. (1997b). The composer's viewpoint [1946]. In J. Bernard (Ed.), Collected Essays and Lectures, 1937-1995 (pp. 3-5), Rochester, N.Y.: University of Rochester Press.

Carter, E. (1997c). Two essays on Goffredo Petrassi [1960 and 1986]. In J. Bernard (Ed.), Collected Essays and Lectures, 1937-1995 (pp. 187-197). Rochester, N.Y.: University of Rochester Press.

Edwards, A.F. \& Carter, E. (1972). Flawed words and stubborn sound: A conversation with Elliott Carter. New York: W.W. Norton.

Keller, P. E., \& Burnham, D. K. (2005). Musical meter in attention to multipart rhythm. Music Perception, 22(4), 629-661. https://doi.org/10.1525/mp.2005.22.4.629

Link, J. (1994), Long-range polyrhythms in Elliott Carter's recent music, Diss., City Univ. of NY.

Mead, A. (2012), Time management: rhythm as a formal determinant in certain works of Elliott Carter. In M. Boland and J. Link (Eds.), Elliott Carter Studies, 138-167. https://doi.org/10.1017/CBO9781139030755.009 
Poudrier, È. (2009). Local polymetric structures in Elliott Carter's 90+ for piano (1994), In: B. Heile (Ed.), Modernist legacy: Essays on new music, (pp. 205-223), Aldershot, England: Ashgate.

Poudrier, È. (2017). Tapping to Carter: Mensural determinacy in complex rhythmic sequences. Empirical Musicology Review, 12(3-4), 277-315. https://doi.org/10.18061/emr.v12i3-4.5814

Poudrier, È., \& Repp, B. H. (2013). Can musicians track two different beats simultaneously? Music Perception, 30(4), 369-390. https://doi.org/10.1525/mp.2013.30.4.369

Repp, B. H. (2005). Sensorimotor synchronization: A review of the tapping literature. Psychonomic Bulletin Review, 12(6), 969-992. https://doi.org/10.3758/BF03206433

Repp, B. H., \& Su, Y. (2013). Sensorimotor synchronization: A review of recent research (2006-2012). Psychonomic Bulletin Review, 20, 403-452. https://doi.org/10.3758/s13423-012-0371-2

Stevens, L. T. (1886). On the time-sense. Mind, 11, 393-404. https://doi.org/10.1093/mind/os-XI.43.393 